Student Success

ISSN: 2205-0795

Volume 6, Issue 2, pp. 87-91

August 2015

\title{
Work Integrated Learning: What do the students want? A qualitative study of Health Sciences students' experiences of a non-competency based placement
}

\author{
Elizabeth Abery, Claire Drummond and Nadia Bevan \\ Flinders University, Adelaide, Australia
}

\begin{abstract}
*
Work Integrated Learning (WIL) offers students the opportunity to explore and expand on theoretical concepts encountered throughout their academic studies in an applied real-life context. WIL also assists students in their transition from educational to professional practice informed by experience, engagement and reflection. Traditionally, disciplines such as Medicine, Nursing, Education, and Law have incorporated WIL into their programs. Literature outlines the benefits of a WIL placement to measure learned competencies, which are integral to such fields of practice. Currently, the scope for a WIL experience is expanding into other non-clinical courses due to increasing pressure for universities to produce "work ready" graduates. However, in generalist degrees such as Health Sciences, where clinical or explicit skill competencies are not required, the WIL experience is generic. This study sought the perceptions of past Health Sciences students' WIL experiences in order to develop appropriate resources for future students.
\end{abstract}

*This 'New Idea and Emerging Initiative' was first presented at the 2015 STARS Conference in Melbourne, Australia in July 2015 and was selected by the Conference Committee as one of the toprated reports. The authors have kindly given their permission to have this report published in the conference issue of the Journal and it has undergone a further review by the editors to confirm it aligns with the Journal format.

Please cite this article as:

Abery, E., Drummond, C., \& Bevan, N. (2015). Work Integrated Learning: What do the students want? A qualitative study of Health Sciences students' experiences of a non-competency based placement. Student Success, 6(2), 87-91. doi: $10.5204 /$ ssj.v6i2.288

Student Success: A journal exploring the experiences of students in tertiary education

(cc) Br are free to use, with proper attribution, in educational and other non-commercial settings. ISSN: 2205-0795 


\section{Work Integrated Learning}

Work Integrated Learning (WIL) through practicum or industry placement is a concept embraced and encouraged by Australian Universities, across many disciplines. Features of WIL programs include learning and being educated at a workplace, specifically by an "expert partner"; learning before, during and after the workplace experience, and being assessed formally, including self-assessment, workplace assessment and educational assessment (Haddara \& Skanes, 2007; Johnston, 2011; Smith et al., 2009). The undertaking of WIL offers students the opportunity to explore and expand on theoretical concepts encountered throughout their academic studies in real-life context and application (Garnett, 2012), assisting students in their transition from educational to professional practice informed by experience, engagement and reflection (Billet, 2011). Further, WIL can enhance confidence, increase independence and teamwork skills, and develop personal and professional skills and identity (Hynie, Jensen, Johnny, Wedlock \& Phipps, 2011; Kaliyamoorthy \& Sridevi, 2011).

Traditionally Medicine, Nursing, Education, and Law have been representative areas incorporating WIL. However due to employers expecting "work ready" students, the scope for WIL experience is expanding (Garnett, 2012; Billet, 2011). Smith et al. (2009) claim that WIL encompasses more than enhancing and developing skills but potentially is a "transformative pedagogy, which entails...personal development and experiential learning" (p. 15). This is of particular relevance to the regulated professions where a perceived identity fits the profession. Professional identity is vital to developing professionalism and professional practice and WIL may facilitate such a transformative learning environment. Professional identity develops with experience; placements provide quality experience opportunities but cannot be controlled (Trede,
2012; Smith et al., 2009). Therefore in professions that are not regulated by competencies or explicit industry skill requirements, and placement opportunities are varied, the experience may or may not transform into learning that enhances future professional practice and identity (Trede, 2012). Transformative learning theory proposes that change will occur where opportunity is provided to challenge existing perceptions or assumptions as a result of experiencing or observing new phenomenon (Cranton, 2011). But as questioned by Billett (2011), while WIL opportunities can be provided to students, is that enough to meet needs, expectations and future career aspirations?

Sufficient preparation, suitable supervision and mentoring arrangements are the three most crucial strategies of an effective placement (Patrick et al., 2009). Independent learning is not sufficient for students. Expert industry partners and placement providers allow for students to view working procedures, engage in knowledge on effective work practices, hierarchies and to work in a team environment under supervision (Billett, 2011). The preparation component includes ample resourcing and opportunities are available for the WIL program to be implemented (Patrick et al.) and sustained. Preparation for WIL also means defining expectations, and ensuring that all stakeholders have realistic expectations of what to anticipate before, during and postplacement (Patrick et al.). Many students are not fully prepared to undertake a placement, unaware of the personal and professional requirements needed to be successful. Sufficient preparation includes the ability to present to the work force as professional, competent and well prepared (Chipchase et al., 2012); placing unprepared students in the workplace can be risky, and may impact all stakeholders' (Patrick et al.). There is a shared responsibility for preparation and planning between the student and the educational institution (Chipchase et 
al.) to facilitate readiness. A student who is not well prepared will have a poorer placement, and place a higher demand on the expert partner and university placement co-ordinator (Chipchase et al.; Parker, 2011). Being fully prepared for placement allows students to obtain the maximum learning experience and make optimum use of the opportunity to practice and enhance their acquired skills and knowledge (Chipchase et al.).

\section{Background to the study}

Von Treuer, Sturre, Keele and McLeod (2011) have identified a lack of evaluation of WIL seen through the eyes of the student. This study extrapolated the "lived experience" of students who had completed a Health Sciences WIL placement in order to elicit student perceptions of placement expectations prior to, during and after the WIL experience. The aim was to determine the resources (practical, personal and theoretical) required to prepare and support students throughout that experience and ensure a positive WIL outcome when undertaking a generic non-competency based placement. The placement represents a core topic undertaken by final year Health Sciences students. The cohort of students comes from a range of degree majors such as Health Promotion, Health Management and Life Sciences. In this instance, the Life Sciences major is undertaken by students aspiring to transfer as postgraduates into Physiotherapy or Occupational Therapy. At the point of the WIL placement, the students' knowledge and skills are nonspecific to that profession. Providing information and opportunities for students to consider future employability options whilst undertaking a placement enhances the benefit of the learning experience and supports the principles of WIL (Billet, 2011; Garnett, 2012). The WIL experience is of great relevance to these students, as their generic degree program has no guarantee of acceptance into their desired pathway. Students may struggle to see relevance to future practice (Kift, 2009; Wilson
\& Fowler, 2005) or in determining their own professional identity (Trede, 2012; Smith, et al., 2009) when undertaking a generic placement.

The WIL opportunity is unique for these students as there are currently no other placement opportunities that this cohort can undertake within their degree. The topic requires 140 hours of placement within a health or community setting and whilst a core topic to the degree, clinical or industry explicit competencies and skills are not required. As the topic is undertaken by a range of students and within a range of agencies, each student, each placement and each working environment may vary. However, based on the outcomes of this study, student needs, expectations and desired outcomes were common.

Fifty-nine students who had completed a Health Sciences WIL placement during 2011-2014 were invited to participate in the study. Twentytwo students completed an online survey and from this data set, 19 agreed to participate in a face-to-face interview. The narrative in-depth qualitative research method allowed students to "tell their story" (Patton, 2002, p. 118).

\section{Study outcomes}

The outcomes of the study reflected WIL literature in that the benefits of offering WIL placement opportunities were acknowledged. Students felt valued in the workplace and took ownership of the work undertaken. They acknowledged outcomes from the placement that could benefit them, regardless of their future profession, indicating that in most instances they did feel more prepared for the workforce whatever that may be. Areas identified were: a greater understanding of how workplaces function; the importance of communication; a sense of empathy for some of the population groups encountered within various health and community settings; a better understanding of their future professional options; and in a few cases, a change of 
Work Integrated Learning: What do the students want? A qualitative study of Health Sciences students' ...

professional aspirations. A range of organisational, interpersonal and individual factors was shown to support a positive WIL placement and outcome. At the organisational level, students greatly appreciated the opportunity to undertake a placement as supported by this participant response:

It bridges the gap between theory and practice. You can have all the theory in the world but without the opportunity for practice you are up the proverbial creek without a paddle.

However, students needed structural and practical support to be prepared prior to placement and reflected on the sources of such support. These included pre-placement information sessions and online resources being available. Understandably, when asked how they felt prior to the placement, the overwhelming response was "excited but nervous". Many students found the prospect of entering a real-world environment confronting and questioned their ability to fit in. While interpersonal resources such as the university and agency supervisors were highly valued prior to and during the placement, students accepted that, as an individual, they needed to take responsibility in preparing for the placement. It was also interesting to note that students saw themselves as a resource and accepted that they needed to be proactive prior to the placement by researching the host organisation and during the placement by developing and maintaining a relationship with not only their immediate agency supervisor but also others within the organisation to ensure a positive and productive outcome. A number of graduates suggested that they would like to hear stories from past student experiences and, as a result, a series of short videos is currently being produced to support future students. Students submit a reflective report to the topic co-ordinator at the end of the placement and this provided another insight into the "lived experience" of the WIL placement. Students gained confidence, skills and knowledge were enhanced and they were able to reflect on how they had contributed to the organisation. Several students also suggested that, as a result of their placement, they were performing better in other topics being undertaken and past topics finally "made sense" by them being able to actually see the theory applied to practice. Further, students post placement were more inclined to access the University Careers and Employment Liaison Services. An additional initiative to be employed in response to this is to involve staff from the University Careers and Employment Liaison Services in preparation sessions prior to placement commencement to encourage students to make the most of placement opportunities within and outside of their current career aspirations.

\section{Discussion and implication for practice}

WIL opportunities are provided to students across many university disciplines however little is known about whether non-competency based placements can meet their needs, expectations and future career aspirations. This study sought to elicit student perceptions of placement expectations prior to, during and after the WIL experience by investigating what resources are required to ensure a positive WIL experience, regardless of degree major and future professional aspirations.

The outcomes of this study are significant, as they will inform future WIL placements. Findings are applicable to the preparation of Health Sciences students in determining what resources are required at an organisational, interpersonal and individual level to support students prior to, during and post placement. The results may also be used to counsel students about how to maximise their WIL experiences to prepare for future work readiness and employability. By seeking rich, descriptive information from students who have recently completed a WIL placement, the "lived experience" has emerged. These students' 
perceptions and stories support future development and management of the topic that formed the context of this study, in addition to other topics that offer non-competency based placements for students. Further research is required to determine whether topic changes made as a result of this study impact future students positively.

\section{Key issues for consideration}

- What is expected or desired from a WIL placement where clinical or industry explicit competencies do not need to be met?

- How as educators do we prepare students to achieve a positive WIL experience in these settings?

\section{References}

Billet, S. (2011). Curriculum and pedagogic bases for effectively integrating practice-based experiences. Australian Learning and Teaching Council. Final report 2011 Griffith University, Brisbane, Australia. Retrieved from http://www.altcexchange.edu.au/group/integrating -practice-experiences-within-higher-education

Chipchase, L., Buttrum, P., Dunwoodie, R., Hill, A., Mandrusiak, A., \& Moran, M. (2012). Characteristics of student preparedness for clinical learning: Clinical educator perspectives using the Delphi approach. BMC Medical Education, 12 112-120. doi: 10.1186/1472-6920-12-112.

Cranton, P. (2011). A transformative perspective on the Scholarship of Teaching and Learning. Higher Education Research \& Development, 30(1). 75-86. doi: 10.1080/07294360.2011.536974

Garnett, J. (2012). Authentic Work-Integrated Learning. In L. Hunt \& D. Chalmers (Eds.), University teaching in focus: A learning-centred approach (pp. 164-179). Melbourne, Australia: ACER Press.

Haddara, M. \& Skanes, H. (2007). A reflection on cooperative education: From experience to experiential learning. Asia-Pacific Journal of Cooperative Education, 8(1), 6776.

Hynie, M., Jensen, K., Johnny, M., Wedlock, J., \& Phipps, D. (2011). Student internships bridge research to real world problems. Education and Training, 53(2/3) 237-248. doi: org/10.1108/00400911111102351

Johnston, N. (2011). Curriculum and curricular orientations in cooperative and work-integrated education. In R. Coll, \& K.Zegwaard (Eds.), International handbook for cooperative and work-integrated learning: International perspectives of theory, research and practice ( $2^{\text {nd }}$ ed. pp. 305-312). Lewell: MA: World Association for Cooperative Education, Inc.

Kaliyamoorthy, S. \& Sridevi, S. (2011). Work-integrated learning program in colleges and universities - an analysis. International Journal of Research in Social Sciences, 1(1). 46-60.

Kift, S. (2009). Articulating a transition pedagogy to scaffold and to enhance the first year student learning experience in Australian higher education, Final Report for ALTC Senior Fellowship Program., Sydney, Australia: Australian Learning and Teaching Council.

Parker, J. (2011). Learning from disruption: Case studies in failing and marginal placements. Interdisciplinary Studies Journal, 1(2) 34-46.

Patrick, C., Peach, D., Pocknee, C., Webb, F., Fletcher, M., \& Pretoo, G. (2009). The WIL (work-integrated learning) report: A national scoping study (final report). Queensland University of Technology, Brisbane, Australia.

Patton, M. (2002). Qualitative research \& evaluation methods ( $3^{\text {rd }}$ ed.). Thousand Oaks, CA: Sage Publications.

Smith, M., Brooks, S., Lichtenbergy, A., Mcllveen, P., Torjul, P., \& Tyler, J. (2009). Career Development Learning: Maximising the contribution of work-integrated learning to the student experience. Project Report, University of Wollongong, Careers Central, Academic Services Division. Wollongong, Australia.

Trede, F. (2012). Role of work-integrated learning in developing professionalism and professional identity. Asia-Pacific Journal of Cooperative Education, 13(3), 159-167.

Von Treuer, K., Sturre, V., Keele, S., \& McLeod, J. (2011). An integrated model for the evaluation of work placements. Asia-Pacific Journal of Cooperative Education, 12(3), 196-204.

Wilson, K. \& Fowler, J. (2005). Assessing the impact of learning environments on students' approaches to learning. Assessment and Evaluation in Higher Education, 30(1), 85-99. doi: $10.1080 / 0260293042003251770$ 